From "MEC 11 Raising the Standard," Proceedings of the 2011 MyoElectric Controls/Powered Prosthetics Symposium Fredericton, New Brunswick, Canada: August 14-19, 2011. Copyright University of New Brunswick.

\title{
UPPER LIMB PROSTHETIC SERVICES POST HAITI EARTHQUAKE
}

\author{
Colleen O'Connell, MD FRCPC ${ }^{1,2}, \mathrm{Al}$ Ingersoll $\mathrm{CP}^{1}$ \\ ${ }^{1}$ Healing Hands for Haiti International Foundation, ${ }^{2}$ Stan Cassidy Centre for Rehabilitation
}

\section{HISTORY OF PROSTHETICS IN HAITI}

The International Society of Prosthetics and Orthotics (ISPO) and the World Health Organization (WHO) have estimated that people needing prostheses or orthotics and related services represent $0.5 \%$ of the population in developing countries [1]. In pre-earthquake Haiti, there was a paucity of data available on persons with amputations, although it was recognized that the services available were not sufficient to meet the needs of the population $[2,3]$. In one survey, the most common cause of amputation was infection, followed by motor vehicle accidents, and only $25 \%$ of persons had received prosthetic rehabilitation [3].

At the time of the earthquake, Healing Hands for Haiti (HHH) operated the only full time prosthetics and orthotics laboratory, with on-site rehabilitation therapy and medical services. Six technicians had been trained in apprenticeship format through visiting expatriate CPOs, and by December 2009 participation in a credentialed training program through Don Bosco University in El Salvador [1] was in the process of being finalized through a collaborative effort of Healing Hands, Physicians for Peace and the International Committee of the Red Cross (ICRC).

Polypropylene technology with modular componentry and custom sockets was the primary type of prostheses fabricated in the Healing Hands clinic. The decision to utilize this method was based on over 10 years of experience in the country with prosthetics and orthotics services, which included long term follow up of patients, training of community based rehabilitation workers and technicians, and an evaluation of both durability, acceptability and affordability of the devices. A system that could be fitted, modified, repaired and replaced in Haiti by local technicians, at an affordable cost, was felt to be superior to alternatives such as fabrication out of country, or short-term 'full service' clinics and workshops conducted by expatriate visitors. Consultation with the ICRC was essential in providing guidance and ultimate support throughout this process.

Upper limb amputations had typically been managed with direct assistance of visiting CPO mentors, often with components being transported from USA or Canada, and fabrication and fitting occurring over a succession of visits by international CPOs. Our experience has been that cosmesis is important, and hook terminal devices were not well received. Despite progress with lower limb services, the capacity to manage upper limb needs remained extremely limited at the time the earthquake struck.

\section{THE EARTHQUAKE AND AMPUTATIONS}

On January 12, 2010 a 7.0 magnitude earthquake struck near the capital of Haiti, a Caribbean nation typically referred to as "the poorest country in the Western Hemisphere". The devastation was profound, and with over 300,000 injured the need for urgent and emergent rehabilitative services was paramount [2,4]. Early estimates of over 2000 persons newly amputated as a result of injuries and secondary complications [2], coupled with significant media attention, led to an unprecedented international response, with over 20 organizations pledging support for prosthetic services. Coordination of these actors represented significant challenges, and many groups did not seek to collaborate with the World Health designated leads for Rehabilitation, or with those providers already operating in the country preearthquake. This led to many types of fabrication techniques, prosthetic components and service delivery models, including some that functioned exclusive of any national provider. $\mathrm{HHH}$ partnered with Handicap International as the HHH clinic was destroyed, and began operation of the joint Physical Rehabilitation Centre (PRC) in February 2010. Pre-earthquake local staff were joined by expatriate volunteers and staff to continue provision of limbs with polypropylene technology, along with rehabilitation therapy, delivered by local staff complemented by expatriate mentors. By June 2010, over 200 patients received limbs at the clinic, and nation-wide an estimated 600 patients had been fit between the various providers.

Ultimately, the estimated numbers of persons with earthquake-related amputations in Haiti was revised to 1200-1500, and by approximately 6 months postearthquake, over half of those had received a lower limb prostheses, a response not seen in any recent natural disaster of this magnitude.

Upper limb loss was not prioritized by any of the organizations, although the $\mathrm{HHH} / \mathrm{HI}$ clinic (PRC) initiated evaluations for need and type of upper limb prostheses in the 12 weeks following the earthquake. Once the emergency phase of services provision was completed, introduction of upper limb fitting and technician training 
From "MEC 11 Raising the Standard," Proceedings of the 2011 MyoElectric Controls/Powered Prosthetics Symposium Fredericton, New Brunswick, Canada: August 14-19, 2011. Copyright University of New Brunswick.

began. We present here the early results of the upper limb amputation program provided by Healing Hands for Haiti and Handicap International, in the aftermath of the 2010 earthquake.

Table 1: Breakdown of levels of amputation observed in 107 consecutive patients with amputations examined in 17 field hospitals between days 3-17 post-earthquake. Amputations made up 35\% of in-hospital injured in need of immediate physical rehabilitation. $\mathrm{N}=307$ consecutive patients [2].

\begin{tabular}{|l|l|l|}
\hline \multirow{2}{*}{$\begin{array}{c}\text { Level of } \\
\text { Amputation }\end{array}$} & \multicolumn{2}{|c|}{ Distribution of Levels (N=107) } \\
\cline { 2 - 4 } & \multicolumn{1}{|c|}{ Number } & \multicolumn{1}{c|}{ Percent } \\
\hline Below Knee & 27 & $25 \%$ \\
\hline Above Knee & 46 & $43 \%$ \\
\hline Upper Limb & 17 & $16 \%$ \\
\hline Unspecified & 17 & $16 \%$ \\
\hline TOTAL & 107 & $100 \%$ \\
\hline
\end{tabular}

\section{UPPER LIMB PROGRAM}

As of May 31, 2011125 persons with upper limb loss have been evaluated by an occupational therapist at PRC. A total of 9 patients have been provided with a prosthesis (s) and received associated training, 5 are awaiting arrival of components and 50 are identified to start the next round of provision. Fitting, fabrication and rehabilitation therapy are done at the HHH/HI PRC. UE sockets have been both ICRC polypropylene or laminated using Otto Bock acrylic resin. Componentry is a combination of Otto Bock from Germany and Hosmer in US. Two HHH local technicians have participated in two-week intensive upper extremity training at Don Bosco P\&O program, sponsored by ICRCSpecial Fund for the Disabled. These technicians actively participate in the upper limb prostheses service delivery under the direction of expatriate prosthetists.

Challenges include the high costs of components, difficulties with importation and customs, limitations with no Haitian credentialed $\mathrm{P} \& \mathrm{O}$ staff and the ongoing cultural stigmas related to acceptance and utilization of prosthetic limbs.
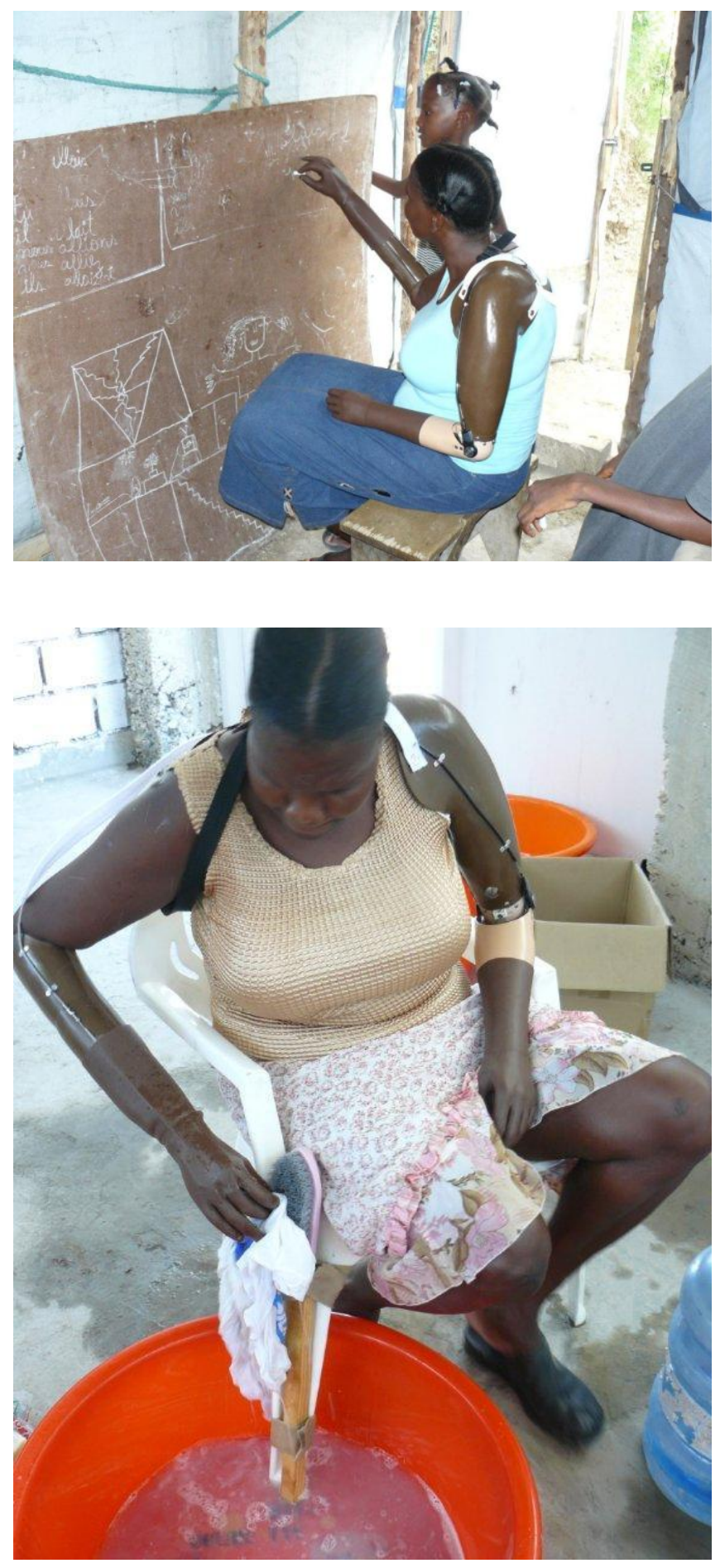

Figure 1 and 2: Participating in training with new prostheses at the Healing Hands for Haiti/Handicap International Physical Rehabilitation Centre, 16 months post earthquake. 
From "MEC 11 Raising the Standard," Proceedings of the 2011 MyoElectric Controls/Powered Prosthetics Symposium Fredericton, New Brunswick, Canada: August 14-19, 2011. Copyright University of New Brunswick.

\section{DISCUSSION}

These authors were both directly involved with the emergency efforts, responsible for rapid assessment of catastrophic injuries requiring emergent rehabilitation services, including prosthetics. We directly examined patients in 17 field and hospital settings in the three weeks following the earthquake, and interviewed surgical staff at each site. Both authors had been working in Haiti in $\mathrm{P} \& \mathrm{O}$ services and training for 10 years prior to the earthquake, and have had ongoing presence in Haiti since the earthquake, through routine visits and medical advisor to HHH (O'Connell), and onsite as Director of P\&O for HHH and Country Director HHH (Ingersoll). We fully concur with the current estimates of earthquake-related amputations, emphasizing that both pre-earthquake and ongoing, there are significant numbers of amputations requiring prosthetic and rehabilitative services. The earthquake has resulted in increased international awareness of the needs and challenges experienced by persons affected by disability in Haiti, and the recognition by the government that a National strategy for both education and training in the rehabilitation professions, and for health services are needed, which includes P\&O.

\section{CONCLUSION}

Organizations involved in $\mathrm{P} \& \mathrm{O}$ services should work in partnership with the National government, collaborate in data collection and dissemination in order to better inform direction of training and service delivery. In keeping with the ISPO/WHO 2003 statement on the relationship between prosthetics and orthotics services and community based rehabilitation [5], training of community rehabilitation workers should complement formal training programs of Category I-III personnel, not replace them. Therefore formalization of credentialed training programs for Haitian $\mathrm{P} \& \mathrm{O}$ staff is a priority of $\mathrm{HHH}$ as well as the ICRC.

Haiti remains a country where life for many remains a day to day challenge. A physical disability impacts ones ability to care for self and family, and with limited national resources in assistive technologies and rehabilitation, an amputation impacts survival. The earthquake in Haiti has resulted in an increase in opportunities for persons with amputation to receive prosthetic rehabilitation. It is imperative that coordinated international efforts continue, to support the development and delivery of credentialed $\mathrm{P} \& \mathrm{O}$ training programs and accessible services throughout the country, not just for earthquake victims, but for all persons affected by disabling conditions.

\section{ACKNOWLEDGEMENTS}

The authors would like to thank the thousands of volunteers and organizations from Haiti and around the world whom supported the emergency relief efforts in Haiti following the earthquake, and in particular the staff and volunteers of ICRC-SFD, Healing Hands for Haiti, Handicap International and Team Canada Healing Hands.

\section{REFERENCES}

[1] World Report on Disability, June 2011 http://www.who.int/disabilities/world_report/2011/en/index.html

[2] O’Connell C, Shivji A, Calvot T. Handicap International Report: "Preliminary findings about persons with injuries," Handicap $\begin{array}{lll}\text { International } & \text { January } & 29,\end{array}$ http://wwww.reliefweb.int/rw/rwb.nsf/db900SID/VVOS82AMLC?OpenDocument.

[3] J. Bigelow et al. "A picture of amputees and the prosthetic situation in Haiti," Disability and Rehabilitation, Vol 26. No. 4, 246252,2004

[4] M. Landry, C. O’Connell, G. Tardif, A. Burns, "Post Earthquake Haiti: the critical role for rehabilitation services following a humanitarian crisis," Disability and Rehabilitation, pp 1-3, 2010.

[5] WHO/ISPO Joint Statement "The Relationship between Prosthetics and Orthotics services and community based rehabilitation," Nov 2003. www.who.int/disabilities/technology/en/ 